\title{
Paediatricians criticise college survey on links with formula milk firms
}

Clarification-We would like to clarify in this news story (BMJ 2016;354:i4555, doi:10.1136/bmj.i4555) that The World Health Organisation's Maternal, infant and young child nutrition: guidance on ending the inappropriate promotion of foods for infants and young children does not replace the Code of Marketing of Breast-milk Substitutes. The guidance provides clarification regarding products covered by the Code and subsequent Health Assembly resolutions. 